Universidade Tecnológica Federal do Paraná - UTFPR

Campus Ponta Grossa - Paraná - Brasil

ISSN: 1981-3686 / v. 03, n. 01: p. 77-85, 2009
Revista Brasileira deTecnologia

Agroindustrial

\title{
ESTABILIDADE DO CALDO FERMENTADO POR Xanthomonas arboricola pv pruni APÓS ARMAZENAMENTO
}

\section{FERMENTATION BROTH STABILITY FROM Xanthomonas arboricola pV pruni AFTER STORAGE}

\author{
Fernanda Germano Alves ${ }^{1}$; Paula Michele Abentroth Klaic ${ }^{2}$ Amanda Ávila Rodrigues ${ }^{1}$; Angelita \\ da Silveira Moreira ${ }^{1,3}$; Claire Tondo Vendruscolo ${ }^{1,2,3}$ \\ ${ }^{1}$ Universidade Federal de Pelotas - UFPel - Programa de Pós-Graduação em Biotecnologia - PPGB - Centro \\ de Biotecnologia - Pelotas - Brasil - fegeal@mikrus.com.br \\ ${ }^{2}$ Universidade Federal de Pelotas - UFPel - Departamento de Ciência e Tecnologia Agroindustrial - DCTA \\ - Pelotas - Brasil - paulabentroth@yahoo.com.br \\ ${ }^{3}$ Universidade Federal de Pelotas - UFPel - Departamento de Ciência dos Alimentos - Pelotas - Brasil - \\ angelita70@terra.com.br
}

\begin{abstract}
Resumo
A xantana é um hidrocolóide amplamente utilizado como modificador reológico na indústria alimentícia, farmacêutica e petrolífera. Ela é produzida através da fermentação aeróbia de açúcares por bactérias do gênero Xanthomonas. O objetivo deste trabalho foi avaliar a estabilidade de características químicas - $p H$, percentual de cinzas, proteínas, acetil e piruvato - $e$ físicas - concentração de xantana, viscosidade e pseudoplasticidade - de caldos fermentados por Xanthomonas arboricola pv pruni cepa GJ, visando determinar a viabilidade de armazenamento desses à temperatura ambiente, após trinta dias. Os resultados demonstraram melhoria nas propriedades reológicas do caldo após trinta dias, sem prejuízo de suas propriedades químicas, demonstrando, assim, a viabilidade de armazenamento do mesmo.
\end{abstract}

Palavras-chave: caldo fermentado; Xanthomonas arboricola pv pruni; armazenamento

\section{Introdução}

A xantana é um heteropolissacarídeo microbiano extracelular produzido por fermentação aeróbia de açúcares por bactérias do gênero Xanthomonas (SUTHERLAND, 1982), sendo considerado um importante modificador reológico, muito empregado nas indústrias alimentícia, farmacêutica e petrolífera devido às suas características de estabilidade e pseudoplasticidade (NITSCHKE, RODRIGUES e SCHINATTO, 2001).

Quimicamente este polímero é formado por unidades de manose, glucose, ácido glucurônico, ácido pirúvico e acético. No entanto, mudanças na composição qualitativa e 
quantitativa podem ocorrer dependendo da bactéria e dos parâmetros empregados durante a fermentação, tais como, meio de produção, aeração, agitação, temperatura e pH (CALLET, MILAS e RINAUDO, 1989). A composição também pode ser influenciada pelos procedimentos pósfermentativos. O tratamento térmico do caldo fermentado é um processo pós-fermentativo utilizado principalmente para inviabilizar as células bacterianas (GARCÍA-OCHOA et al., 2000). Para algumas cepas esse tratamento também resulta em um incremento da viscosidade do caldo, bem como da qualidade reológica da xantana obtida (BORGES et al., 2009).

Klaic et al. (2009) estudaram o armazenamento do caldo fermentado por X. arboricola pv pruni cepa EDE e concluíram que houve melhorias nas propriedades reológicas sem prejuízo de suas propriedades químicas e físicas durante o período armazenado.

O objetivo deste trabalho foi avaliar a estabilidade das características químicas e físicas dos caldos fermentados por Xanthomonas arboricola pv pruni cepa GJ armazenado à temperatura ambiente, visando determinar a viabilidade de armazenamento destes, a partir da comparação das características dos caldos recém fermentados e após trinta dias.

\section{Materiais e Métodos}

Os caldos fermentados foram produzidos em fermentador Biostat B de 5L, segundo patente WO2006047845 (VENDRUSCOLO et al., 2006), utilizando parâmetros operacionais diferenciados, sendo que para o caldo A utilizou-se a condição intermediária de agitação estabelecida na patente e aeração de 1 vvm; e para o caldo B a condição mínima de agitação e aeração de 3 vvm. Ambos os caldos foram esterilizados e divididos em duas parcelas - $A_{0}, A_{1}$ e $B_{0}$ e $B_{1}$, sendo $A_{1}$ e $B_{1}$ armazenados à temperatura ambiente por um período de trinta dias.

Para verificar a viabilidade do armazenamento dos caldos fermentados avaliaram-se as características químicas e físicas através da determinação dos teores de xantana, por precipitação alcoólica seguida de secagem e análise gravimétrica (VENDRUSCOLO et al., 2000); cinzas (AOAC, 1997); proteínas pelo método de Kjeldahl; acetil e piruvato por análise colorimétrica (McCOMB e McCREADY , 1957 e SLONEKER e ORENTAS, 1962, respectivamente) e viscosidade em Viscosímetro Visco Tester 6L Thermo Haake, com spindle L3, em 10, 30, 60 e 100 rpm, durante 30 segundos em cada rotação.

As determinações foram realizadas em triplicata e os dados tratados estatisticamente através de Análise de Variância (ANOVA) e Teste de Tukey, com nível de significância de 5\% (STATISTIX 8, 2004). 


\section{Resultados e Discussão}

Os teores de xantana, $\mathrm{pH}$, proteínas, acetil e piruvato, e viscosidade dos caldos recém fermentados e armazenados estão apresentados nas Figuras 1, 2, 3 e 4, respectivamente.

Figura 1: Produção de xantana dos caldos fermentados.

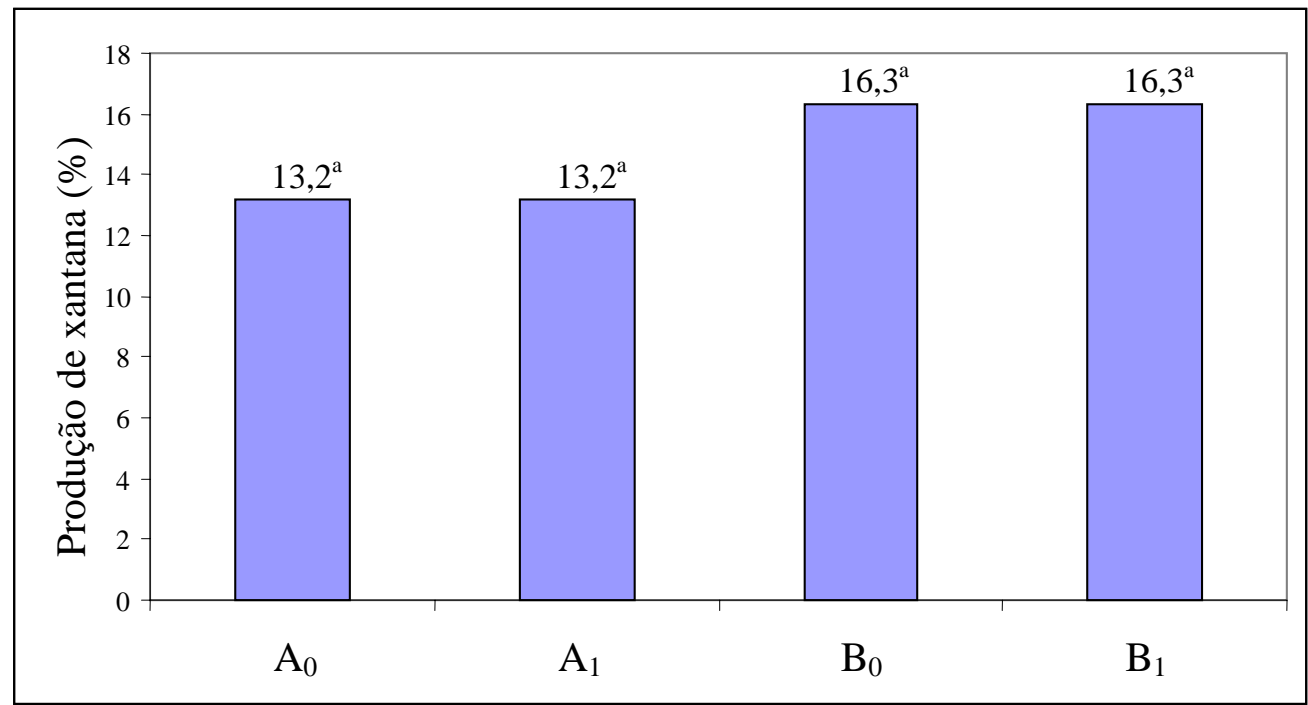

$\mathrm{A}_{0}$ : agitação intermediária, $1 \mathrm{vvm}$, recém fermentado; $\mathrm{A}_{1}$ : agitação intermediária, 1vvm, armazenado; $\mathrm{B}_{0}$ : agitação mínima, 3vvm, recém fermentado; $\mathrm{B}_{1}$ : agitação mínima, 3vvm, armazenado.

* Letras iguais não diferem estatisticamente pelo Teste de Tukey $(\mathrm{p}<0,05)$.

Analisando a Figura 1, observa-se que o armazenamento dos caldos fermentados A (agitação intermediária, 1vvm) e B (agitação mínima, 3vvm), por 30 dias, não influenciou no teor de xantana, obtendo-se o mesmo valor para os caldos armazenado e recém fermentado (13,2 e 16,3g.L ${ }^{-1}$; respectivamente). Os valores de pH (Figura 2) não sofreram alteração após armazenamento.

Figura 2: Valores de $\mathrm{pH}$ dos caldos fermentados.

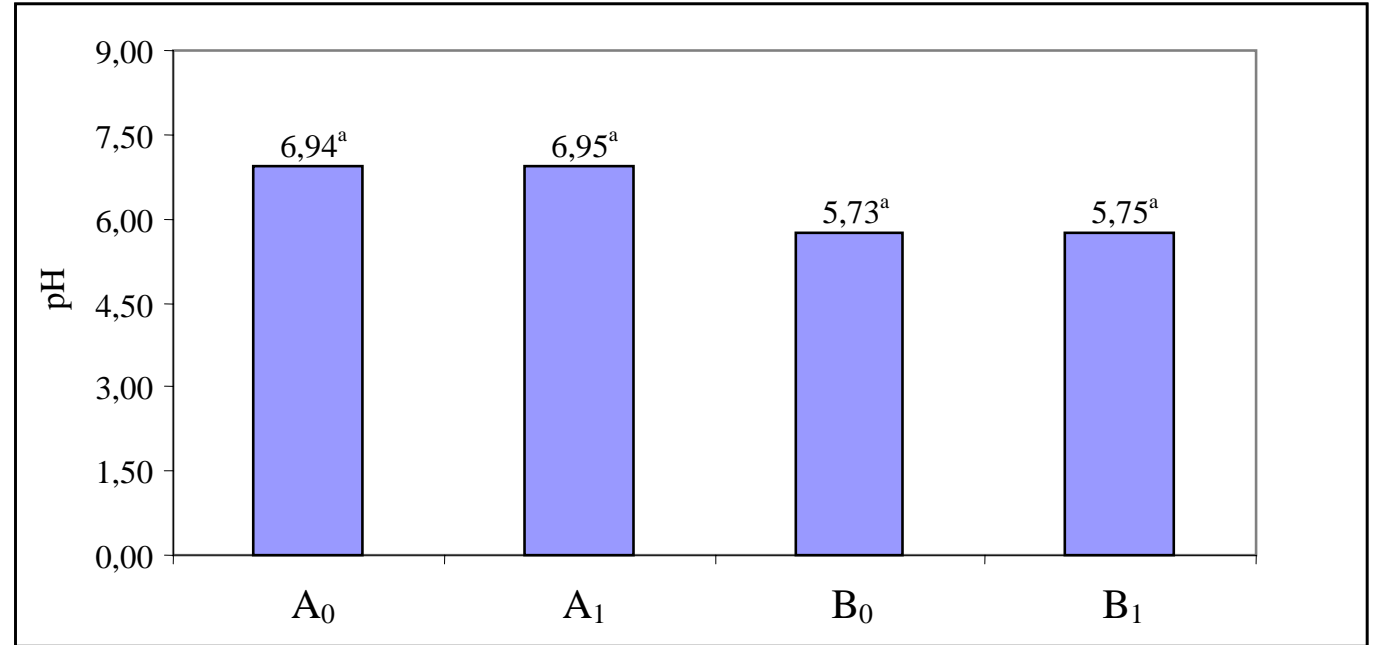

$\mathrm{A}_{0}$ : agitação intermediária, 1vvm, recém fermentado; $\mathrm{A}_{1}$ : agitação intermediária, 1vvm, armazenado; $\mathrm{B}_{0}$ : agitação mínima, 3vvm, recém fermentado; $\mathrm{B}_{1}$ : agitação mínima, 3vvm, armazenado.

* Letras iguais não diferem estatisticamente pelo Teste de Tukey $(\mathrm{p}<0,05)$. 
Figura 3: Teor de proteínas dos caldos fermentados.

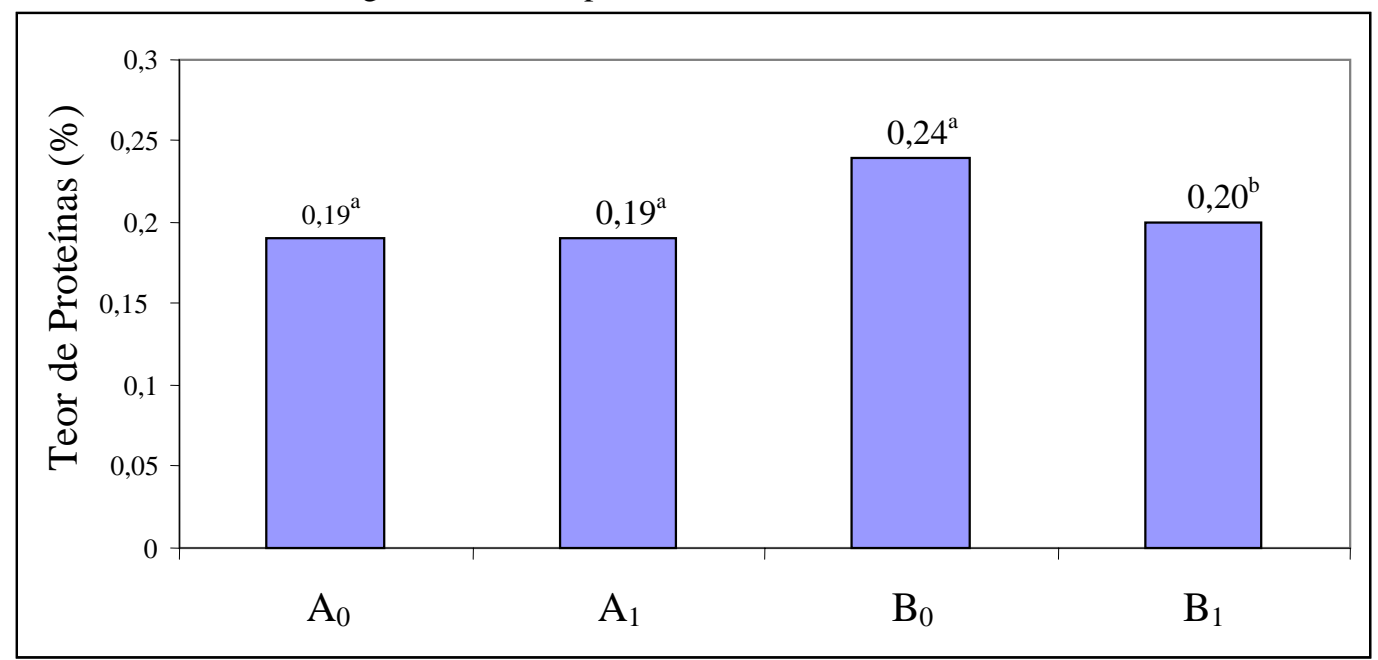

$\mathrm{A}_{0}$ : agitação intermediária, 1vvm, recém fermentado; $\mathrm{A}_{1}$ : agitação intermediária, 1vvm, armazenado; $\mathrm{B}_{0}$ : agitação mínima, 3vvm, recém fermentado; $\mathrm{B}_{1}$ : agitação mínima, 3vvm, armazenado.

* Letras iguais em colunas de mesma cor não diferem estatisticamente pelo Teste de Tukey $(\mathrm{p}<0,05)$.

O teor de proteínas, conforme Figura 3, não diferiu estatisticamente entre o caldo recém fermentado $\left(\mathrm{A}_{0}\right)$ e armazenado $\left(\mathrm{A}_{1}\right)$ produzido sob condição intermediária de agitação e aeração de $1 \mathrm{vvm}$. No entanto, para o caldo produzido sob condição mínima de agitação e aeração de 3vvm, observou-se diferença nesse teor que, embora significativa, não influenciou de forma negativa nas propriedades reológicas.

Figura 4: Teores de acetil e piruvato dos caldos fermentados

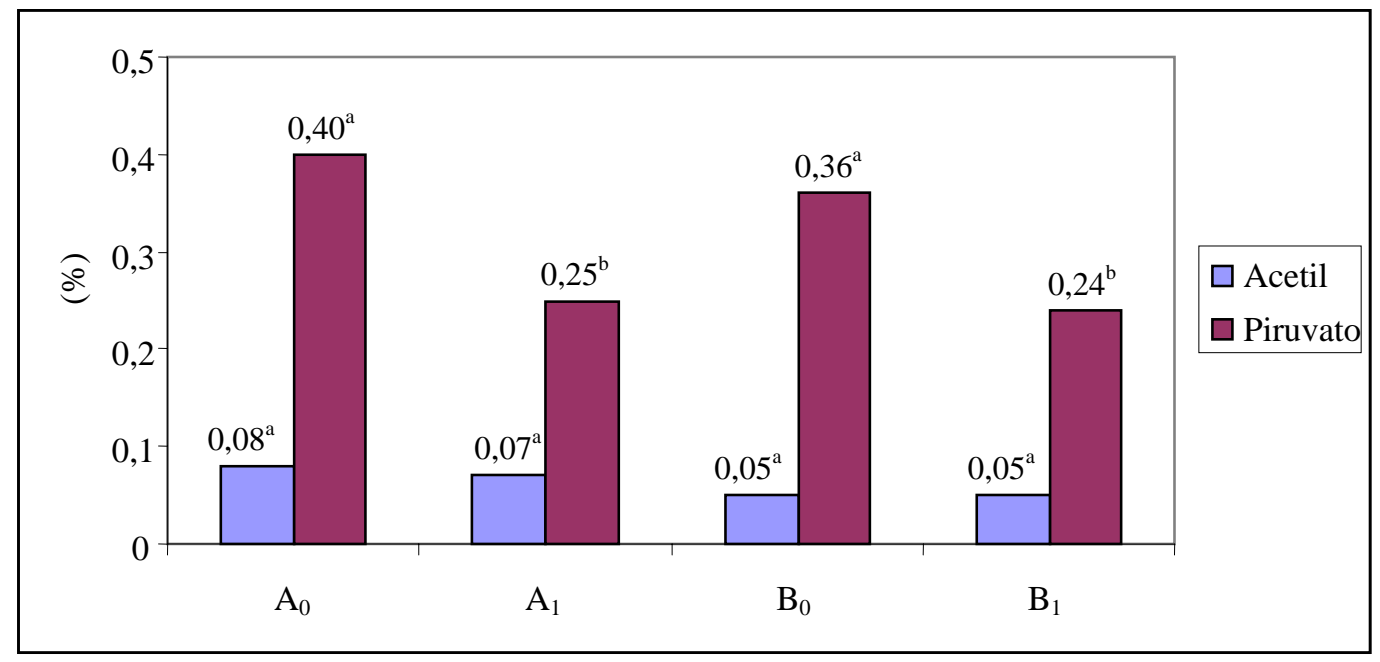

$\mathrm{A}_{0}$ : agitação intermediária, 1vvm, recém fermentado; $\mathrm{A}_{1}$ : agitação intermediária, 1vvm, armazenado; $\mathrm{B}_{0}$ : agitação mínima, 3vvm, recém fermentado; $\mathrm{B}_{1}$ : agitação mínima, 3vvm, armazenado.

* Letras iguais em colunas de mesma cor não diferem estatisticamente pelo Teste de Tukey $(\mathrm{p}<0,05)$.

Para ambos os caldos, não houve diferença significativa no teor de acetil (Figura 4) após armazenamento. No entanto, Klaic et al. (2009) utilizando a cepa EDE do patovar pruni, observou uma redução de $25 \%$ no teor de acetil após cento e vinte dias de armazenamento nas mesmas 
condições. Quanto ao teor de piruvato (Figura 4) observou-se diferença significativa entre os caldos recém fermentados e armazenados. Esta redução pode ter sido causada por oxidação do piruvato.

Figura 5 - Viscosidade em diferentes rotações dos caldos fermentados

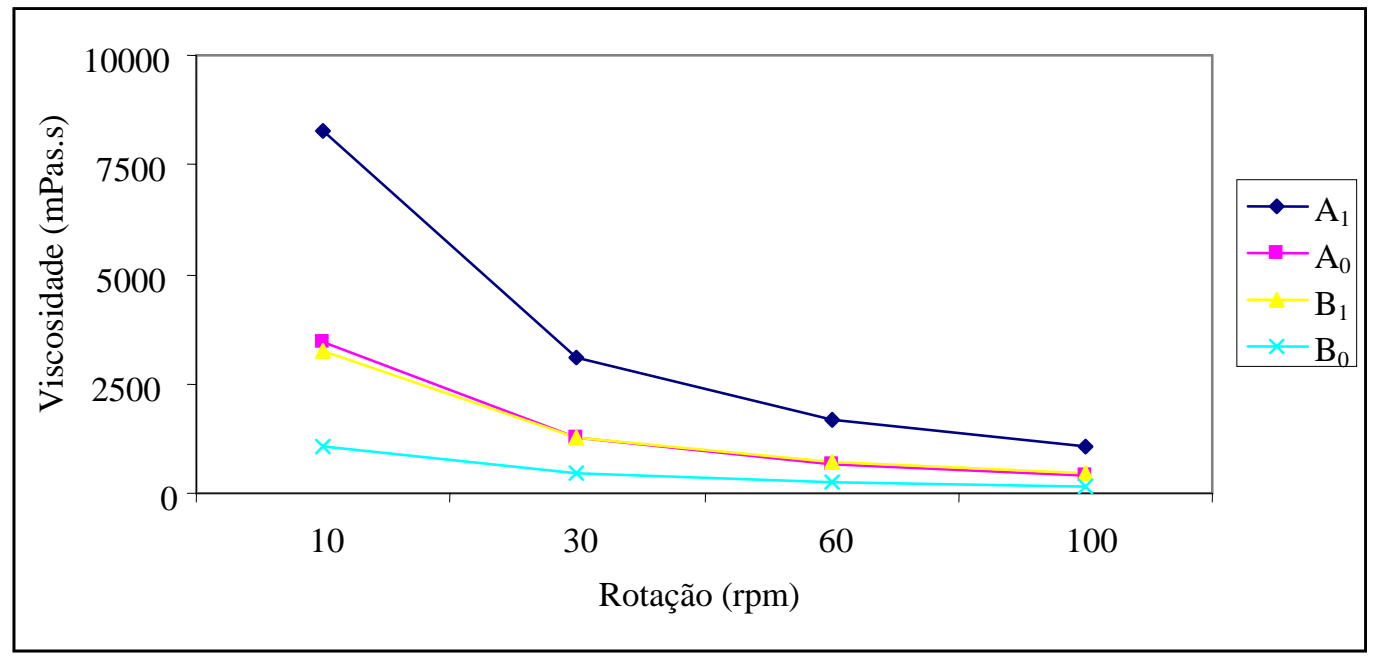

$\mathrm{A}_{0}$ : agitação intermediária, 1vvm, recém fermentado; $\mathrm{A}_{1}$ : agitação intermediária, 1vvm, armazenado; $\mathrm{B}_{0}$ : agitação mínima, 3vvm, recém fermentado; $\mathrm{B}_{1}$ : agitação mínima, 3vvm, armazenado.

Figura 6 - Pseudoplasticidade dos caldos fermentados $A_{0}$ e $A_{1}$ em diferentes rotações

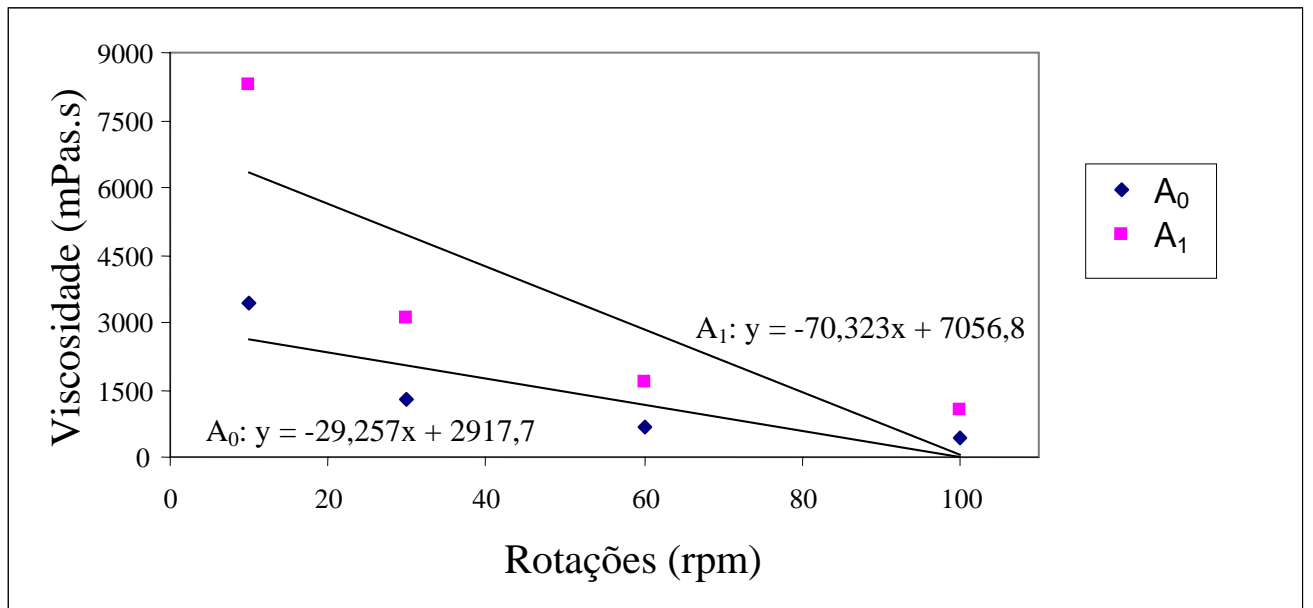

$\mathrm{A}_{0}$ : agitação intermediária, $1 \mathrm{vvm}$, recém fermentado; $\mathrm{A}_{1}$ : agitação intermediária, 1vvm, armazenado; $\mathrm{B}_{0}$ : agitação mínima, 3vvm, recém fermentado; $\mathrm{B}_{1}$ : agitação mínima, 3vvm, armazenado. 
Figura 7 - Pseudoplasticidade dos caldos fermentados $B_{0}$ e $B_{1}$ em diferentes rotações

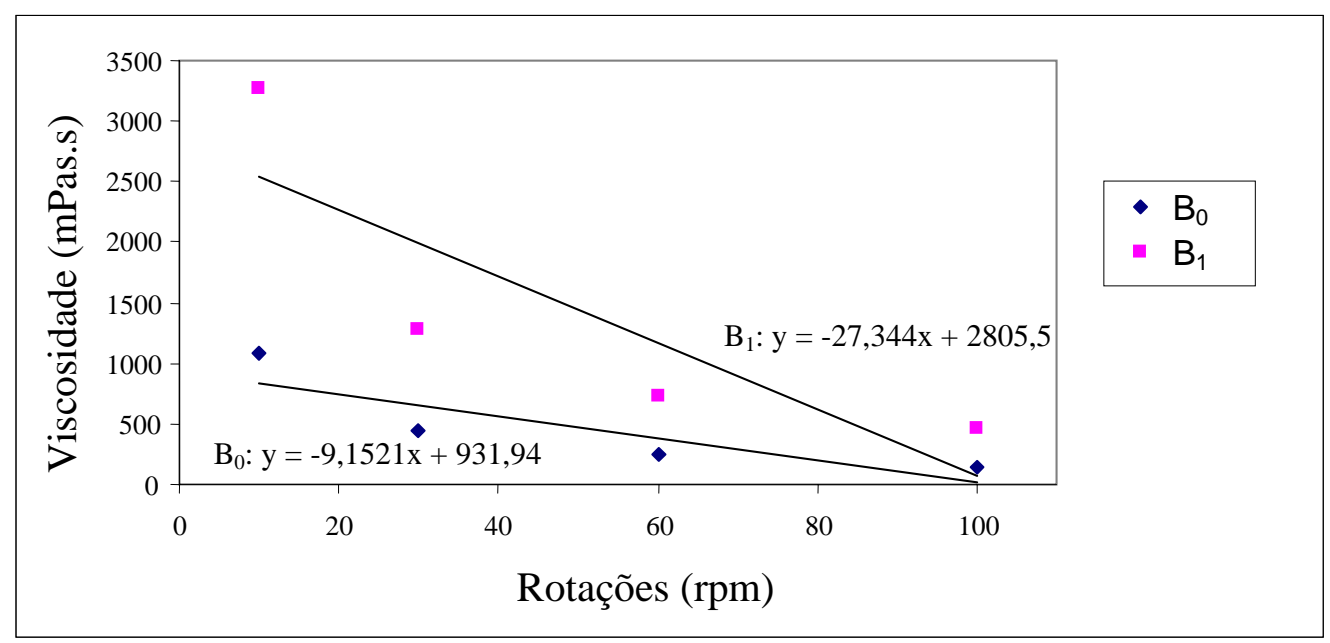

$\mathrm{A}_{0}$ : agitação intermediária, 1vvm, recém fermentado; $\mathrm{A}_{1}$ : agitação intermediária, 1vvm, armazenado; $\mathrm{B}_{0}$ : agitação mínima, 3vvm, recém fermentado; $\mathrm{B}_{1}$ : agitação mínima, 3vvm, armazenado.

A viscosidade é um importante indicador da qualidade do caldo fermentado, uma vez que tem relação com a qualidade e quantidade da xantana no caldo (ANTUNES et al., 2000). As condições operacionais de agitação e aeração influenciaram a viscosidade dos caldos. Obtiveram-se caldos mais viscosos utilizando agitação intermediária combinada com aeração de 1vvm. Entretanto, observou-se que, independentemente das condições operacionais utilizadas para produção dos caldos, ambos apresentaram aumento significativo da viscosidade após o período de armazenamento; resultados semelhantemente ao observado no estudo realizado por Klaic et al. (2009).

Todos os caldos fermentados apresentaram pseudoplasticidade, que se caracteriza pela redução da viscosidade com o aumento da taxa de cisalhamento. Esta característica é, em geral, muito desejada e, no presente trabalho, aumentou após o armazenamento, como pode ser observado através dos coeficientes angulares das retas. Quanto maior o ângulo da reta (Tabela 1), maior será a pseudoplasticidade do caldo fermentado.

Tabela 1: Coeficientes angulares em função da viscosidade em diferentes rotações dos caldos fermentados.

\begin{tabular}{cc}
\hline Caldos & Coeficiente angular \\
\hline $\mathrm{A}_{0}$ & 29,257 \\
$\mathrm{~A}_{1}$ & 70,323 \\
$\mathrm{~B}_{0}$ & 9,1521 \\
$\mathrm{~B}_{1}$ & 27,344
\end{tabular}

$\mathrm{A}_{0}$ : agitação intermediária, 1vvm, recém fermentado; $\mathrm{A}_{1}$ : agitação intermediária, 1vvm, armazenado; $\mathrm{B}_{0}$ : agitação mínima, 3vvm, recém fermentado; $B_{1}$ : agitação mínima, 3vvm, armazenado. 


\section{Conclusão}

Os caldos fermentados por Xanthomonas arboricola pv pruni cepa GJ, sob diferentes condições operacionais e com posterior tratamento térmico, apresentaram-se, após armazenamento durante 30 dias à temperatura ambiente, similares quimicamente aos caldos recém fermentados. Entretanto, apresentaram significativo aumento na viscosidade e pseudoplasticidade, demonstrando a viabilidade do armazenamento destes caldos nas condições testadas. Estudos complementares estão sendo conduzidos para verificar a viabilidade do armazenamento em períodos mais longos.

\section{Referências}

ANTUNES, A. E. C.; MOREIRA, A. S.; VENDRUSCOLO, J. L. S.; VENDRUSCOLO, C. T. Viscosidade aparente de biopolímeros produzidos por diversas cepas de Xanthomonas campestris pv. pruni. Ciência e Engenharia, v. 9, n. 1, p. 83-87, 2000

AOAC. Official methods of analysis of the Association of Official Analytical Chemists International. 16. ed. Washington: AOAC, 1997.

BORGES, C. D.; PAULA, R.C.M.; FEITOSA, J. P. A.; VENDRUSCOLO, C. T. The influence of thermal treatment and operational conditions on xanthan produced by $X$. arboricola pv pruni strain 106. Carbohydrate Polymers, v. 75, p. 262-268, 2009.

CALLET, F.; MILAS, M.; RINAUDO, M. On the role of thermal treatments on the properties of xanthan solutions. Carbohydrate Polymers, v. 11, p. 127-137, 1989.

GARCÍA-OCHOA, F.; SANTOS V. E.; CASAS J. A.; GOMEZ E. Xanthan gum: production, recovery and properties, Biotechnology Advances, n. 7, v. 18, p. 549-579, 2000.

KLAIC, P. M. A.; RODRIGUES, A. A.; AlVES, F. G.; PREICHARDT, L. D.; SILVA, L. F.; MOREIRA, A. S.; VENDRUSCOLO, C. T. Armazenagem do caldo de fermentação é possível? Revista Higiene Alimentar, v. 23, n.170/171, pg 469 março/abril - Encarte, 2009.

MCCOMB, E. A.; MCCREADY, R. M.. Determination of acetyl in pectin and in acetylated carbohydrate polymers, Analytical Chemistry, v. 29, n. 5, p. 819-821, 1957.

NITSCHKE, M.; RODRIGUES, V.; SCHINATTO, L. F.; Formulação de meios de cultivo à base de soro de leite para a produção de goma xantana por Xanthomonas campestris $\mathrm{C}_{7} \mathrm{~L}^{1}$. Ciência e Tecnologia de Alimentos, v. 21, n 1, p. 82 85, 2001.

SLONEKER, J. H.; ORENTAS, D. G. Pyruvic acid, a unique component of an exocellular bacterial polysaccharide. Nature, London, v. 194, n. 4827, p. 478-479, 1962.

SUTHERLAND, I. W. Biosynthesis of microbial exopolysaccharides. Advances Microbial Physiology, v. 23, p. 80142, 1982.

VENDRUSCOLO, C. T; VENDRUSCOLO, J.L.S; MOREIRA, A. S. Processo de produção de biopolímero tipo xantana, biopolímero obtido, seus usos; meio de cultura para crescimento de Xanthomonas e uso da mesma para produção de biopolímero. World Intellectual Property Organization (WO2006047845), 2006.

VENDRUSCOLO, C. T. et al. Heteropolysaccharide produced by Xanthomonas campestris pv pruni C 24. Nishinari, K. Hydrocolloids. Amsterdam: Elsevier. v.1, p.187-191, 2000. 


\begin{abstract}
The xanthan is a hydrocolloid widely used as rheological modifier in the pharmaceutical, petroleum and food industry. It is produced by aerobic fermentation of sugars by Xanthomonas bacterium. The objective this work was evaluate the stability of the chemical characteristics $-\mathrm{pH}$, ash, proteins, acetyl and pyruvate percentage - and physical - xanthan concentration, viscosity and pseudoplasticity - of the fermented broth by Xanthomonas arboricola pv pruni strain GJ, aiming at to determine the storage viability these in the room temperature, after thirty days,. The results had demonstrated improvement in the rheological properties of the broth with after thirty days, without damage of its chemical properties, demonstrating, thus, the storage viability of the same.
\end{abstract}

Key-words: fermented broth; Xanthomonas arboricola pv pruni; storage

\title{
Dados completos dos autores
}

Nome completo: Fernanda Germano Alves

Filiação institucional: Universidade Federal de Pelotas

Departamento: Programa de Pós-Graduação em Biotecnologia - PPGB

Função ou cargo: Doutoranda - PPGB

Titulação: Mestre em Engenharia e Ciência de Alimentos

Área de atuação: Microbiologia Industrial

Endereço completo para correspondência: Universidade Federal de Pelotas - Centro de Biotecnologia - Campus Universitário, s/nº, Caixa Postal 354, cep 96010-900, Pelotas, RS

Telefones para contato: (53) 3275-7585

e-mail: fegeal@mikrus.com.br

Nome completo: Paula Michele Abentroth Klaic

Filiação institucional: Universidade Federal de Pelotas

Departamento: Departamento de Ciência e Tecnologia Agroindustrial - DCTA

Função ou cargo: Mestranda - PPGDCTA

Titulação: Química Industrial de Alimentos

Área de atuação: Microbiologia Agroindustrial

Endereço completo para correspondência: Universidade Federal de Pelotas - Centro de Biotecnologia - Campus Universitário, s/nº, Caixa Postal 354, cep 96010-900, Pelotas, RS

Telefones para contato: (53) 3275-7585

e-mail: paulabentroth@yahoo.com.br

Nome completo: Amanda Ávila Rodrigues

Filiação institucional: Universidade Federal de Pelotas

Departamento: Programa de Pós-Graduação em Biotecnologia 
Função ou cargo: Mestranda - PPGB

Titulação: Bióloga

Área de atuação: Microbiologia Industrial

Endereço completo para correspondência: Universidade Federal de Pelotas - Centro de Biotecnologia - Campus Universitário, s/nº, Caixa Postal 354, cep 96010-900, Pelotas, RS

Telefones para contato: (53) 3275-7585

e-mail: amanda.bio2005@gmail.com

Nome completo: Angelita da Silveira Moreira

Filiação institucional: Universidade Federal de Pelotas

Departamento: Departamento de Ciência dos Alimentos - DCA

Função ou cargo: Professora Adjunto

Titulação: Doutora em Biotecnologia

Área de atuação: Microbiologia Aplicada, Farmacognosia, Farmacotecnia, Química Analítica

Endereço completo para correspondência: Universidade Federal de Pelotas, Faculdade de Ciências

Domésticas, Departamento de Ciências dos Alimentos, Campus Universitário, s/nº, Caixa-Postal 354, cep 96010-900 - Capão do Leão, RS - Brasil

e-mail: angelita70@terra.com.br

Nome completo: Claire Tondo Vendruscolo

Filiação institucional: Universidade Federal de Pelotas

Departamento: Departamento de Ciência dos Alimentos - DCA

Função ou cargo: Professora Adjunto Nível 4

Titulação: Doutora em Engenharia de Alimentos

Área de atuação: Tecnologia de Alimentos, Tecnologia de Produtos de Origem Vegetal, Microbiologia Aplicada

Endereço completo para correspondência: Universidade Federal de Pelotas, Faculdade de Ciências Domésticas, Departamento de Ciências dos Alimentos. Centro de Biotecnologia, Prédio 19, Campus Universitário, s/nº, Caixa-Postal 354, cep 96010-900 - Capão do Leão, RS - Brasil

Telefones para contato: (53) 3275-7585

e-mail: claire@ufpel.tche.br 